\title{
Body image as a source of shame: A new measure for the assessment of the multifaceted nature of body image shame
}

\begin{tabular}{|r|l|}
\hline Journal: & Clinical Psychology \& Psychotherapy \\
\hline Manuscript ID: & CPP-0789.R2 \\
\hline Watey - Manuscript type: & Assessment \\
\hline Complete List of Authors: & $\begin{array}{l}\text { Duarte, Cristiana; University of Coimbra, Cognitive-Behavioural research } \\
\text { Centre, Psychology Department } \\
\text { Pinto-Gouveia, José; Cognitive-Behavioural Research Centre, Psychology } \\
\text { Department, University of Coimbra } \\
\text { Ferreira, Cláudia; Cognitive-Behavioural Research Centre, Psychology } \\
\text { Department, University of Coimbra } \\
\text { Batista, Diana; Faculty of Psychology and Educational Sciences, University } \\
\text { of Coimbra }\end{array}$ \\
\hline Keywords: & $\begin{array}{l}\text { Body image shame, body image, eating psychopathology, psychometric } \\
\text { properties, Confirmatory Factor Analysis }\end{array}$ \\
\hline &
\end{tabular}

\section{SCHOLARONE ${ }^{m}$}

Manuscripts 
Body image as a source of shame: A new measure for the assessment of the multifaceted nature of body image shame

Short title: A new measure for the assessment of body image shame

$$
\begin{gathered}
\text { Cristiana Duarte } \text { M.S. Ph.D. Student }^{* 1} \\
\text { José Pinto-Gouveia MD, Ph.D. }{ }^{1} \\
\text { Cláudia Ferreira M.S., Ph.D. } \\
\text { Diana Batista, M.S. }
\end{gathered}
$$

${ }^{1}$ University of Coimbra, Portugal

CINEICC - Cognitive - Behavioural Research Centre

* Correspondence concerning this article should be addressed to:

Cristiana Duarte

CINEICC, Faculdade de Psicologia e Ciências da Educação, Universidade de Coimbra

Rua do Colégio Novo, Apartado 6153

3001-802 Coimbra, Portugal

E-mail: cristianaoduarte@gmail.com (Cristiana Duarte)

Telephone: $(+351) 239851450$

Fax: (+351) 239851462

\section{Acknowledgements:}

This research has been supported by the first author's (Cristiana Duarte) Ph.D. Grant (SFRH/BD/76858/2011), sponsored by FCT (Portuguese Foundation for Science and Technology). 


\begin{abstract}
Theoretical and empirical accounts highlight the link between shame and body image difficulties, and disordered eating behaviours. Specifically, body image shame seems to play a particularly important role in this association. The current study aimed at developing and validating a new measure of body image shame and its phenomenology, the Body Image Shame Scale (BISS).

Distinct samples of women from the general and student populations were used to test the BISS factorial structure using Principal Component Analysis (PCA) and Confirmatory Factor Analysis (CFA), and to examine the psychometric properties of the BISS.

PCA results indicated that the scale presents a two-factor structure assessing an externalized and an internalized dimension underlying body image shame, which explains a total of $62.41 \%$ of the variance. A CFA further corroborated the adequacy of this structure, which revealed good global and local adjustment indices. The BISS also presented very good internal consistency, construct and discriminant validities and good test-retest reliability. The scale also showed good concurrent and divergent validities. Furthermore, the scale discriminates between women with higher or lower levels of disordered eating behaviours. Finally, a mediation analysis revealed that the BISS fully mediates the previously established association between external shame and eating psychopathology.
\end{abstract}

The BISS is a psychometrically robust and short measure of body image shame and its external and internal dimensions. 


\section{Key Practitioner Message}

- The BISS is a brief and reliable self-report instrument of body image-related shame.

- The BISS assesses the phenomenology of body image shame considering an externalized dimension and an internalized dimension, which may have important clinical implications.

- The BISS presents very good internal consistency, construct and discriminant validities, test-retest reliability, concurrent and divergent validities, and accurately distinguishes between women with higher and normative levels of disordered eating behaviours.

- Body image shame, as assessed by the BISS, contributes to a better understanding of eating psychopathology with findings suggesting that the association between external shame and eating psychopathology fully depends on the extent to which one's body image becomes the source of shame, with the consequent activation of defensive attitudes and behaviours.

\section{Keywords}

Body image shame; body image; eating psychopathology; psychometric properties; Confirmatory Factor Analysis 


\section{INTRODUCTION}

Body image may be an indicator of women's attractiveness and rank in the social world (Buote, Wilson, Strahan, Gazzola, \& Papps, 2011; Ferreira, PintoGouveia, \& Duarte, 2013a; Pinto-Gouveia, Ferreira, \& Duarte, 2014). Evolutionary and cultural approaches have suggested that evolution has shaped the human brain to be extremely sensitive to social cues of approval (versus criticism) and acceptance (versus rejection), and to develop mechanisms that stimulate positive affect and beliefs about the self in the mind of others (Gilbert, 1992, 1997, 2000), motivating them to establish advantageous relationships with the self (e.g., as an ally, friend, sexual partner; Baumeister \& Leary, 1995).

In order to assure the creation of a positive image of oneself, one has to be aware of the qualities valued by the social group within a certain context (Cohen, 2001) to track whether others perceive him/her as attractive and to know which domains one should invest in (Gilbert, 1997, 2000, 2002). The display of an attractive physical appearance, a part of us that is readily observable and assessed by others, has always been a particularly important indicator of social attractiveness, especially among women (Ferreira et al., 2013a; Gatward, 2007; Gilbert, 2002; Gilbert, Price \& Allan, 1995; Myers \& Crowther, 2009).

In modern Western societies, feminine attractiveness has been represented by thinness, which became a mirror of desirable psychological characteristics, success, power and happiness (e.g., Engeln-Maddox, 2006). This sociocultural context clearly defines that a slender body shape should be pursued (to be valued by the social group; Stice, Schupak-Neuberg, Shaw, \& Stein, 1994; Wiseman, Gray, Mosimann, \& Ahrens, 1992) and that not fitting within these patterns (e.g., overweight) should be avoided in order to reduce the threat of being criticized, blamed, attacked or rejected (Puhl \& Hauer, 2009). In this sense, perceiving that one is failing to reach such desirable sociocultural standards and a positive view of oneself, is a major threat and may have enduring effects (Gilbert, 1992, 1997; Gilbert \& McGuire, 1998; Schore, 1994). Hence, one's physical appearance may be a source of shame.

Shame has been defined as a multifaceted, self-conscious and socially shaped emotion that emerges in the context of competition for social attractiveness. Shame acts as a warning sign that the self exists negatively in the mind of others, thus 
standing at risk of being rejected, excluded, passed by or harmed (Lewis, 2003; Liotti \& Gilbert, 2011; Gilbert, 1998, 2002, 2007; Tangney \& Dearing, 2002). Such negative evaluations about how one thinks others see and judge the self (e.g., as bad, unattractive, flawed and a worthless and rejectable social agent) have been conceptualized as external shame. In this case, the focus of attention is on the external world with the individual anticipating that his/her exposure to others may lead to social diminishment or rejection and possibly engaging in attempts to avoid displaying unattractive features to others (Gilbert, 1997, 1998, 2002; Lewis, 1992). These evaluations can be internalized with one starting to view oneself in the same devaluing manner others might. Here the focus of attention, feelings and negative judgements are self-directed, and encompass what has been referred to as internal shame (Gilbert, 1998, 2002; Mikulincer \& Shaver, 2005).

This deleterious emotion of shame has been regarded as playing a central role in a series of psychopathological conditions (e.g., Kim, Thibodeau, \& Jorgensen, 2011; Matos, Pinto-Gouveia, \& Gilbert, 2013), namely body image and eating related psychopathology (e.g., Goss \& Allan, 2009; Grabhorn, Stenner, Stangier, \& Kaufhold, 2006; Swan \& Andrews, 2003; Troop, Allan, Serpell, \& Treasure, 2008). In particular, recent studies show that shame has a major impact on body image dissatisfaction and disordered eating behaviours, both in patients with eating disorders and nonclinical samples (e.g., Ferreira et al., 2013a, 2013b; Pinto-Gouveia et al., 2014).

Specifically, perceptions that one's body is unattractive and falls short of what the sociocultural context defines as a desirable physical appearance, has also been regarded as a source of distress and body image and eating-related psychopathology, namely among women (Bessenoff \& Snow, 2006; Castonguay, Brunet, Ferguson, \& Sabiston, 2012; McKinley, 1998; Noll \& Fredrickson, 1998). These experiences have been related to the emotion of shame regarding one's body image.

Following a biopsychosocial approach (Gilbert, 1998, 2002, 2007), shame regarding body image involves negative evaluations that one has physical attributes (body shape, size or weight) believed to be viewed by others as unattractive and that place oneself in a vulnerable and unwanted social rank; these evaluations may also be inwardly focused (Gilbert, 2002; Gilbert \& Thompson, 2002). As shame evolved as 
an affective-defensive response to protect the self against such (perceived) loss of attractiveness in the eyes of others (Gilbert, 1997, 1998), a series of defensive attitudinal and behavioural outputs may be activated in response to these evaluations regarding one's physical appearance. These may include wanting to hide or conceal the body or to avoid social situations in which one's physical appearance may be exposed to the scrutiny of others (Gilbert, 2002). However, these responses may have a paradoxical effect, enhancing shame and the pathogenic impact of these experiences in one's life.

Nevertheless, the role of body shame and related phenomenology on eating and body image-related difficulties and wellbeing, remains poorly documented. Also, different measures or assessment methods have been used to explore this construct. Nevertheless, they seem not to be clearly focusing on body image shame and related cognitions and behaviours and/or have some methodological limitations. One of these measures is the Objectified Body Consciousness Scale (OBC; McKinley \& Hyde, 1996). This scale is based on the concept of objectified body consciousness, which entails women's tendency to scrutinize their bodies as outside observers and to constantly monitor how close/distant they are to/from the sociocultural ideal standard. This tendency is assumed to have an impact on women's shame, which is assessed in the OBC by the Body Shame subscale ( $\alpha=.75$; e.g., "I feel ashamed of myself when I haven't made the effort to look my best"). The Derriford Appearance Scale (DAS59 and DAS24; Carr, Harris, \& James, 2000; Carr, Moss, \& Harris, 2005) also targets self-consciousness of appearance (e.g., "My self-consciousness of appearance makes me irritable at home"), and has been suggested as useful in the assessment of some aspects related to body shame. Even though these are valid measures, they focus only on a sense of self-consciousness related to body image, and fail to specifically address body image shame and its phenomenology.

Furthermore, the Experiences of Shame Scale (Andrews, Qian, \& Valentine, 2002) includes a subscale of shame regarding body image, which assesses (through four items) the experiential, cognitive and behavioural dimensions of body image shame. Even though this may offer important information, the use of single items to assess each dimension does not allow a clear examination of the phenomenology of this emotion related to body image. More recently, Conradt et al. (2007) developed 
the Weight and body-related Shame and Guilt Scale (WEB-SG), which aims at evaluating shame regarding body shape or weight (e.g., "I am ashamed of myself when others get to know how much I really weigh"), and guilt concerning one's eating and exercise patterns, and weight control. Although WEB-SG is a valid measure, it was designed for obese individuals and thus it is not generalizable to other samples.

\begin{abstract}
Aims
The main aim of this study was the development of a scale that specifically assessed body image shame: the Body Image Shame Scale (BISS). It has been suggested that the focus of shame - a more externally focused shame, or an internalized shame as negative self-devaluation and criticism - has important clinical implications, namely in the onset and course of body image disturbances and disordered eating behaviours (Goss \& Allan, 2009; Goss \& Gilbert, 2002; Troop et al., 2008). Thus, this distinction is an important aspect to consider in the evaluation of shame regarding one's physical appearance. Therefore, we intended to develop a scale that would allow for the operationalization of body image shame as involving two dimensions: one focused on the external world that would assess perceptions that one's body image may elicit negative evaluations or criticism in others, with avoidance of or distress felt in social contexts in which this may occur; and a dimension inwardly focused, involving negative perceptions about one's body image and its effect on one's social standing, and consequent behaviours of body image concealment. The current study examines the factor structure of this new measure through an exploratory factor analysis and a confirmatory factor analysis, in a wide sample of female college students and women from the general population. Furthermore, the psychometric properties of the BISS were analysed. Finally, this study aimed at further contributing to the understanding of the role that shame plays in eating psychopathology, by considering the specific mediator effect of body image shame.
\end{abstract}




\section{METHOD}

\section{Participants}

A total of 958 women participated in the study. Distinct samples comprising both college students and participants from the general population were used to conduct the studies.

Sample 1. The scale was first examined in 443 participants, with ages ranging from 18 to 59 , and with a mean age of $23.54(S D=8.04)$ and of $14.04(S D=1.79)$ years of education. Mean Body Mass Index (BMI) was $22.38(S D=3.43)$.

Sample 2. Data from 515 participants were used to conduct the Confirmatory Factor Analysis and to further test BISS validity. Participants presented ages ranging from 18 to 37 , with a mean age of 21.83 years old $(S D=4.16)$ and of $14(S D=1.99)$ years of education. Participants presented a mean Body Mass Index (BMI) of 21.73 $(S D=2.96)$.

Sample 3. Fifty-two participants were additionally asked to complete the retest version of the BISS.

\section{Measures}

Participants completed a battery of self-report questionnaires designed to measure body image shame, eating psychopathology, shame, social comparison through physical appearance, and psychopathological symptoms.

$B M I$. We calculated participants' BMI by dividing the current weight (in $\mathrm{kg}$ ) by height squared (in m).

Eating Disorder Examination Questionnaire (EDE-Q; Fairburn \& Beglin, 1994; Portuguese version by Machado, 2007). The EDE-Q is a self-report version of the well-established investigator based interview, the Eating Disorders Examination (EDE; Cooper \& Fairburn, 1987, Fairburn \& Cooper, 1993) that provides a similarly comprehensive assessment of the specific psychopathology of disordered eating behaviours. The EDE-Q comprises 36 items focusing on the past 28 days. This selfreport questionnaire includes four subscales: Restraint (5 items), Eating Concern (5 items), Weight Concern (5 items) and Shape Concern (8 items). The items comprising these subscales are rated for frequency of occurrence (items 1-15; on a scale ranging from $0=$ "No days" to $6=$ "Every day") or for severity (items 29-36; on a scale 
ranging from $0=$ "Not at all" to $6=$ "Markedly"). A global EDE-Q score can also be obtained by calculating a mean of the four subscale scores. Higher scores indicate greater levels of disturbances. Research supports that this scale holds good psychometric properties.

Other as Shamer Scale (OAS; Goss, Gilbert \& Allan, 1994; Portuguese version by Matos, Pinto-Gouveia, \& Duarte, 2011). The OAS is a self-report measure that measures external shame, that is, global judgements regarding how people believe others view them, involving evaluations that others look down on, and negatively evaluate the self (Goss et al., 1994). It comprises 18 items regarding which respondents are asked to indicate the frequency on a five-point Likert scale $(0=$ "Never" to 4 = "Almost always") of their shame feelings and experiences (e.g., 'I think that other people look down on me'). Higher scores on this scale indicate high external shame. In the original study, as well as in the Portuguese version, the scale showed good reliability, with a Cronbach's alpha of .92 (Goss et al., 1994) and .91 (Matos et al., 2011).

Social Comparison through Physical Appearance Scale (SCPAS; Ferreira et al., 2013a). This scale assesses the subjective perception of one's social ranking in comparison to others using physical appearance as a reference. It comprises two scales assessing this social comparison process relatively to proximal targets (friends, colleagues and other known girls; 12 items), and distal targets (models, actresses and other celebrities; 11 items). Participants are instructed to select a number, using a Likert scale ranging from 1 to 10 , that best translates the way they feel in relation to the comparison targets. Higher scores represent more favourable comparisons. In the original study, the scale revealed good psychometric properties with Cronbach's alpha values of .94 and .96 for the Peers and Models subscales, respectively.

Depression Anxiety and Stress Scales - 21 (DASS21; Lovibond \& Lovibond, 1995; Portuguese version by Apóstolo, Mendes, \& Azeredo, 2006). The DASS21 is a short form of the Lovibond and Lovibond's (1995) 42-item self-report measure scale that assesses levels of Depression (DEP; e.g., 'I could not feel any positive feelings'), Anxiety (ANX; e.g, 'I felt my mouth dry') and Stress symptoms (STR; e.g., 'Had difficulty in calming me'). The three subscales comprise 7 items each. Using a 4-point Likert scale $(0=$ 'did not apply anything to me' to $4=$ 'very applied to me most 
often') respondents are asked to indicate the frequency they experienced each symptom over the past week. Higher results indicate higher levels of emotional distress. The original as well as the Portuguese versions of the scale reveal adequate internal consistency $(\mathrm{DEP}=.88, \mathrm{ANX}=.82$, and $\mathrm{STR}=.90$, in the original version; and $\mathrm{DEP}=.85, \mathrm{ANX}=.74$, and $\mathrm{STR}=.81$, in the Portuguese version).

The Cronbach's alpha values for the variables considered in the current study are reported in Table 3.

\section{Procedure}

Data collection followed ethical requirements. After the Ethic Committees and boards of the institutions involved approved the study, the researchers presented the study to the students and the women from the general population as a research about emotions and behaviours related to body image and wellbeing. Participants were fully informed about the voluntary nature of their cooperation and the confidentiality of the data collected, which was only used for research purposes. After participants gave their informed consent, author CD administered and collected the self-report measures, with the assistance of undergraduate students. Standardized instructions were given to all participants. The female students completed the assessment protocol at the end of a lecture. The women from the general population comprised a convenience sample collected within the staff of distinct institutions (e.g., schools, private companies, retail services), and completed the questionnaires during a break, with permission from the professional institutions' boards.

\section{Development of the BISS}

The BISS was developed to measure the experience and phenomenology of body image shame. Authors CD, JPG and CF generated two sets of items designed to measure i) an externalized dimension involving negative feelings and perceptions that one's body image may be an object of negative scrutiny, criticism by others and diminishment, along with the activation of defensive responses to such threat (e.g., avoidance of social contexts); ii) an internalized dimension of body shame, which comprises self-focused negative self-evaluations based on one's body image and 
consequent behaviours to control body image exposure (i.e., concealment). Item generation was based on literature review and on clinical experience. This process resulted in a pool of 38 items ( 7 of which assessed a positive accepting relationship with one's body image, added to ascertain the scale's face validity and thus not included in the following analysis). This preliminary version of the scale was administered to a group of patients with eating disorders with high levels of shame. They were asked to complete the scale and comment on whether the items reflected their body-related shame experiences. The items were further subject to discussion and revision. Minor changes of wording were conducted and some items were dropped. The scale resulted in 27 items, which were submitted to an exploratory factor analysis with the aim of reaching a short reliable measure.

The scale instructions ask respondents to rate each item according to whether it translates the frequency with which they experience feelings or experiences of shame regarding body image, using a 5 -point Likert scale (ranging from $0=$ 'Never' to $4=$ 'Almost always').

\section{Analytic Strategy}

In the development of the scale a Principal Components Analysis with a Maximum Likelihood extraction and Direct Oblimin rotation was conducted. Furthermore, internal consistency was evaluated by computing Cronbach's alpha coefficients and item-total correlations were computed for each of the items comprising the two subscales of the BISS.

Moreover, the obtained structure was confirmed through a Confirmatory Factor Analysis. Construct reliability and convergent validity were further established through the calculation of the Composite Reliability and of the Average Variance Extracted. The software AMOS (Analysis of Momentary Structure, software version 18, SPSS Inc. Chicago, IL) was used in these analyses.

The relationship between the BISS and other self-report measures was assessed by computing Pearson product-moment correlation coefficients. Retest reliability was analysed through the comparison of the first and second administration (after a onemonth period) mean values of the scale through Dependent Samples t-Tests and through Pearson product-moment correlations. The ability of the scale to discriminate 
between a group of women from the general population with normative levels of eating psychopathology and a group with higher eating difficulties was assessed through t-Tests for Two Independent Samples.

The mediator effect of body shame, as measured by the BISS, on the association between a global measure of shame (OAS; independent variable) and eating psychopathology (EDE-Q; criterion variable) was examined. The mediator effect was tested through linear regressions following Baron and Kenny's (1986) four-step model. According to this procedure, mediation is established when the independent variable significantly predicts the dependent variables and the mediator, and when the mediator significantly predicts the dependent variable, when controlling for the independent variable. There is a total mediator effect when the previously significant association between the independent and the dependent variable is no longer significant with the introduction of the possible mediator on the model (Baron \& Kenny, 1986).

The analyses were conducted using IBM SPSS Statistics 20 (Statistical Package for the Social Sciences, Chicago, IL, USA).

\section{RESULTS}

\section{Preliminary data analyses}

Preliminary data analyses were conducted to test for the multivariate normality assumption. The obtained Skewness and Kurtosis values did not represent a significant bias to normal distribution ( $\mathrm{Sk}<|3|$ and $\mathrm{Ku}<|10|$; Kline, 2005).

\section{Scale development}

\section{Exploratory Factor Analysis}

A Principal Components Analysis was conducted (sample 1) and a Direct Oblimin rotation was applied since it was expected to find two related dimensions. The suitability of the data to conduct the analysis was confirmed through the Keiser Meyer-Olkin test (.95) and through the Bartlett's sphericity test $\left(\chi^{2}(351)=7907.28, p \leq\right.$ $.001)$. In the first non-rotated analysis the Kaiser-Guttman criteria suggested the 
decision of retaining four factors. Nevertheless, the Catell's scree test suggested that a two-factor structure was more adequate.

Taking this into account the analysis was recalculated with a Direct Oblimin rotation forcing a two-factor solution, which explained $53.77 \%$ of the scale variance. All items presented communalities above .5. The examination of the factorial loadings indicated the progressive deletion of 3 items for presenting factorial loadings below .45 on either of the factors. The removal of these items resulted in an increase of the amount of variance explained to 55.65\%. Furthermore, 2 items were excluded since, in the first case, the item content replicated another item and, in the second case the item loaded on a factor in which it was not theoretically expected to.

In order to reach a short and reliable measure a final analysis was conducted retaining the 7 items of each subscale with the highest factorial loadings and that were theoretically consistent and more strongly captured the constructs under analysis. The final structure explained a total of $62.41 \%$ of the variance. The first factor Externalized Body Shame - explained $50.84 \%$ of the variance and assesses perceptions of inferiority and that one's physical appearance may be the target of negative scrutiny and criticism by others, with the avoidance of social situations in which this may occur. The second factor - Internalized Body Shame - explained a total of $11.57 \%$ and captures the engagement in body concealment driven by selfloathing based on one's physical appearance. Table 1 presents the BISS 14-item structure, communalities and factorial loadings of each item.

\section{Internal consistency}

Results indicated that the 14-item structure obtained revealed a very good internal reliability with a Cronbach's alpha value of .92. Also, the first subscale presented a Cronbach's alpha of .89 and the second one a Cronbach's alpha of .90 . All items showed moderate to high item-total correlations (all above .58), pointing out the quality and suitability of the items. Specifically, results revealed that all single items are associated with the total of each respective subscale, with values ranging from .63 and .80 for the first factor, and .60 and .79 for the second factor. Furthermore, the removal of any item would not increase the internal reliability of the total scale or of each subscale. 
Insert Table 1 approximately here

\section{Confirmatory Factor Analysis and psychometric properties of the BISS}

\section{Confirmatory Factor Analysis}

A CFA was conducted to confirm the previously found two-factor structure of the BISS, having Maximum Likelihood as the estimation method (sample 2). Each item was specified to load on its respective latent first-order factor. The two latent factors previously identified were specified to load on a second-order factor of body image shame. A series of goodness of fit indices were selected to evaluate the suitability of this structure. First, results indicated a significant chi-square goodnessof-fit $\left(X^{2}=369.958 ; p<.001\right)$. Even though this result may suggest that the data is not consistent with the measurement model it is consensual that this indicator is problematic since it may be biased due to sample size (DeCoster, 1998). Other goodness of fit indices were therefore selected to overcome this limitation. The Normed Chi-Square (in which values varying between 2 and 5 show a good global adjustment of the model; Tabachnick \& Fidell, 2007; Arbuckle, 2008) was used. Also, the following relative fit indices were considered: the Normed Fit Index, which indicates a good fit when values are superior or equal to .90 (Arbuckle, 2008); the Comparative Fit index (CFI) and the Tucker and Lewis Index (TLI), both of which indicate a good fit when values range from [.90 - .95], and a very good fit with values above 95 (Brown, 2006) Additionally, the Parsimony Normed Comparative Fit Index (PCFI), in which values between 0.6 and 0.8 indicate a good fit, was analysed. Finally, the values of the Root Mean Square Error of Approximation were examined considering that values between [.05 - .08] indicate a good fit and that a model presents a very good fit with a RMSEA value below .05 ( $p \leq .05$; Arbuckle, 2008).

The indicators revealed that this structure had an acceptable fit (Table 2). Furthermore, the quality of the model was examined through the local adjustment indices. Results indicated that the two first-order factors - Externalized Body Shame and Internalized Body Shame - significantly loaded on the second-order factor (.85 
and .94, respectively). Furthermore, all items revealed Standardized Regression Weights (SRW) ranging from .61 to .88 in the first subscale, and .73 and .87 in the second subscale. That is, all values were above the recommended cut-off point of .40 . Also Squared Multiple Correlations (SMC) results confirmed the instrument reliability, with all items presenting values ranging from .37 to .77 (above .25 the cutoff point; Tabachnick \& Fidell, 2007).

Nevertheless, the modification indices were analysed and results suggested the progressive correlation of the errors of items 8 and 14, and of items 25 and 24 . The correlation of these errors resulted in an improvement of the global adjustment indices, with the model presenting a good to very good fit (Table 2). The quality of the model was also examined through the local adjustment indices. Again, all estimates were significant. In particular, results indicated that all items revealed adequate SRW, which varied from .61 (item 18) to .89 (item 34) in the first subscale, and .74 (items 2, 21 and 8) and .87 (item 22) in the second subscale. That is, all values were above the recommended cut-off point of .40 (Tabachnick \& Fidell, 2007). SMC results confirmed the instrument reliability, with all items presenting values ranging from .38 (item 18) to .79 (item 34).

Insert Table 2 approximately here

Validity Analyses

The Composite Reliability (CR) and Average Variance Extracted (AVE) were calculated manually by computing the respective formulas (Fornell \& Larcker, 1981). Results indicated that the first factor revealed a CR of .94, while the second factor showed a CR of .95. Furthermore, the BISS total score showed a CR of .96. These findings indicate that the scale and respective subscales have very good construct reliability. Regarding the AVE, results indicated a value of .69 for the first factor, and of .75 for the second one, which confirmed the instrument convergent validity.

The discriminant validity of the factors was assessed through the comparison of the AVE of each factor with the squared correlation between the factors. Given that the AVE values were higher than $r^{2}=.62$, results indicated that the two factors have adequate discriminant validity. 


\section{Retest Reliability}

The temporal stability of the scale was tested through Dependent Samples ttests, which showed that there were no significant differences between the scores of the two assessment moments of the BISS ( $t_{\text {Externalized Body Shame(51) }}=0.16, p=.871$; $\left.t_{\text {Internalized Body Shame(51) }}=0.11 ; p=.913 ; t_{\text {Total (51) }}=0.00, p=1.000\right)$. Product-moment Pearson correlations were conducted as a further analysis of test retest reliability, and results indicated high significant positive correlations between the test and retest versions of the BISS subscales ( $r_{\text {Externalized Body Shame }}=.66 ; r_{\text {Internalized Body Shame }}=.73$ ) and global score $(r=.75)$.

\section{Relationships between BISS and other measures}

Product-moment correlation coefficients (Table 3) indicated that the two subscales and the BISS total score were significantly and positively correlated with external shame (OAS). It is noteworthy that the Externalized Body Shame subscale showed a higher positive correlation with a global measure of external shame.

On the other hand, results showed that the subscales and total score of the BISS were negatively linked, with moderate to high correlations, with favourable social comparisons through physical appearance with peers and models.

Regarding the associations between this new measure of body shame and eating psychopathology-related measures, results show that the subscales and global score of the BISS were significantly and positively linked to body image dissatisfaction, with moderate correlations. Also, results showed significant positive correlations with the EDE-Q subscales. In particular, higher positive correlations were found between the BISS overall score and subscales, namely Internalized body shame, and Shape and Weight Concern subscales of the EDE-Q. Furthermore, the subscales and total score of the BISS were significantly and positively linked to BMI, but with low to moderate correlations.

Finally, results showed low to moderate associations between the BISS and its subscales and depressive, anxious and stress symptoms.

Insert Table 3 approximately here 


\section{BISS and eating psychopathology}

To ascertain whether the BISS would discriminate women with higher disordered eating behaviours from other participants with normative scores on the EDE-Q total score, considering community norms (Fairburn \& Beglin, 1994), we compared two samples selected from the total sample. The group with higher levels $(n$ $=102$ ) was selected based on the cut-off point of one standard deviation above EDEQ total score mean. The other group comprised 106 controls randomly selected within the remaining participants.

The two samples presented the same demographic characteristics. Particularly, regarding age, the group with higher disordered eating behaviours levels $(M=21.27$; $S D=3.97)$, and the control group $(M=21.50, S D=4.30)$, did not present significant differences $\left(t_{(206)}=0.392 ; p=.695\right)$. Also, in relation to years of education $(M=$ 13.85, $S D=1.42 ; M=14.25, \mathrm{SD}=1.92$; respectively), there were no significant differences between the groups $\left(t_{(206)}=1.71 ; p=.089\right)$.

Results indicated that participants with higher levels report significantly higher scores of Externalized Body Shame $(M=1.36 ; S D=0.93)$ in comparison to the control group $\left(M=.38 ; S D=.51 ; t_{(206)}=9.28 ; p<.001\right)$, and of Internalized Body Shame $\left(M=2.49 ; S D=0.78\right.$ vs. $M=1.00 ; S D=0.89$, respectively; $t_{(206)}=12.78 ; p<$ $.001)$. Also the two groups present statistically significant differences regarding the BISS global score $\left(t_{(206)}=12.53 ; p<.001\right)$, with the group with higher disordered eating behaviours presenting a mean of $1.92(S D=0.76)$, while the control group presented a mean of $0.69(S D=0.65)$.

\section{Mediator Analysis}

A series of preliminary analyses were conducted to confirm the suitability of the data to conduct regression analyses to test the mediator effect of body image shame (BISS), on the association between a global measure of shame (OAS) and eating psychopathology (EDE-Q; Figure 1). The values of Skewness and Kurtosis as well as the visual inspection of the variables distributions corroborated the assumption of normality (Kline, 2005; Tabachnick \& Fidell, 2007). The assumptions of normality, 
linearity and homoscedasticity, independence of errors and multicolinearity were confirmed (Tabachnick \& Fidell, 2007).

A regression analysis was conducted with OAS entered as the independent variable, and EDE-Q as the dependent variable. This model was significant $\left(F_{(1,513)}=\right.$ $66.66 ; p<.001)$ and accounted for $11.5 \%$ of eating psychopathology' variance. The following analysis confirmed that OAS significantly predicted $\operatorname{BISS}\left(F_{(1,513)}=\right.$ 202.17; $\left.p<.001 ; R^{2}=.28\right)$. A regression analysis entering EDE-Q as the criterion variable, and OAS and BISS as the predictors was then performed. Results indicated that this model was significant $\left(F_{(2,512)}=250.427 ; p<.001\right)$, accounting for $49 \%$ of eating psychopathology' variance. Furthermore, findings showed that the BISS completely mediated the relationship between a global measure of shame and eating psychopathology, since OAS $\beta$ reduced to nonsignificance with the introduction of the mediator. Finally, the significance of the indirect effect of OAS on EDE-Q (through its effect on BISS), was confirmed through the Sobel Test, which indicated that body image shame fully mediates the association between overall shame and eating psychopathology $(z=12.83 ; p<.001)$.

Insert Figure 1 approximately here

\section{DISCUSSION}

There has been a growing interest on how physical appearance may operate as an indicator of one's social rank and attractiveness, as well on the impact this may have on the engagement in disordered eating behaviours and body image disturbances, namely among women (Ferreira et al., 2013a, 2013b; Pinto-Gouveia et al., 2014). The painful emotion of shame related to body image arises in this context of humans' competition for being attractive social agents (Gilbert, 2002). This study presents the development and validation of the Body Image Shame Scale (BISS), a brief and reliable self-report instrument that allows for the assessment of the phenomenology of body image-related shame. Furthermore, this study explored the associations between this new assessment tool and other measures of shame, social rank, overall psychopathology symptoms and body image and eating-related psychopathology. 
The structure of the BISS was first examined though a PCA in a sample of 443 female participants. This initial analysis indicated a clear distinction of two dimensions, as theoretically expected: the Externalized Body Shame (7 items), where the focus of attention is on the external world on how others may negatively evaluate or criticize the self because of one's physical appearance, with the avoidance of social situations that may set the context for such scrutiny; and Internalized Body shame (7 items), a inwardly focused dimension of shame that involves depreciative selfevaluations and concealment behaviours.

The factorial structure obtained was further corroborated through a CFA, which confirmed the adequacy of this two-factor structure underlying a higher-order factor of Body Image Shame. In particular, the global and local adjustment indices proved the suitability of the BISS factorial structure taking into consideration the recommended standards (e.g., Tabachnik \& Fidell, 2007). The correlated errors between two items in each subscale were estimated following standard recommendations (Brown, 2006; Kline, 2005). This resulted in a very good adjustment of the model.

Furthermore, the current study confirmed that the BISS total score and subscales have high internal consistency. Also, results of the item-total correlation analyses corroborated the quality and adequacy of the items to each respective subscale and overall scale. The Composite Reliability was high for both factors, and the Average Variance Extracted, which is an indicator of convergent validity of the factors, was also adequate. The scale also presented adequate discriminant validity and showed to be stable over time.

In addition, the BISS presented good concurrent and divergent reliabilities. In fact, this new measure of body image shame was positively correlated with a measure of external shame, and negatively correlated with favourable perceptions of social rank based on physical appearance (in comparison to peers as well as to women representative of the sociocultural thin ideal - models, actresses or celebrities). In particular, as expected, higher correlations were found between external shame and the Externalized Body Shame subscale, while Internalized Body Shame was more highly (negatively) correlated with the perception of one's rank position within the social world. 
Furthermore, significant and strong associations between the BISS and eating psychopathology were found, namely with the EDE-Q dimensions referring to body shape and weight concerns. Also noteworthy is the fact that body image-related shame was likewise positively correlated with women's levels of anxiety, depression and stress. These findings suggest therefore that shame focused on this specific domain of body image (which can be an important indicator of social rank; Ferreira et al., 2013) is a damaging emotion that may have a negative impact on women's sense of wellbeing. Additionally, it was found that body image shame and its dimensions were significantly associated with increased BMI. This was also an expected result, since a higher BMI brings one closer to features that society determines should be avoided to prevent the creation of negative feelings and evaluations in others about the self, and feelings of inferiority and inadequacy (Gilbert, 2002; Puhl \& Heuer, 2009).

This study also confirmed the new measure's ability to distinguish between cases with higher levels of disordered eating behaviours from participants with lower levels.

Finally, the current study confirmed that this specific scale of body image shame further contributes to the understanding of eating psychopathology. In fact, the mediation analysis confirmed the well-established association between OAS and eating-related difficulties (e.g., Ferreira et al., 2013a, 2013b; Pinto-Gouveia et al., 2014), but it added that this relationship is fully dependent on the presence of body image-related shame and consequent attitudes and behaviours. Hence, perceiving that others view us negatively may lead to eating psychopathology only when one's body image is understood as placing us in a vulnerable and threatening position in the social world, with the consequent activation of a series of defensive outputs (e.g., avoidance and concealment). In this sense, disordered eating behaviours, such as pathological dieting and purging behaviours, may be understood as maladaptive control strategies to attempt to change what is perceived as the cause of shame - one's body image.

This study's findings need to be interpreted taking into consideration some limitations. This was the first study examining the structure of a new measure of body image shame in a large sample of female Portuguese participants, and allowed us to 
confirm that this construct comprises two distinct dimensions. However, to ensure the plausibility of this structure, future research should be conducted to test the model invariance in other samples and in other languages (e.g., English). For instance, future validation of the scale should be conducted in other female samples comprising different age ranges (e.g., adolescents) and in specific risk groups in which physical appearance is a central element for self and others evaluations (e.g., models, actresses, dancers).

Moreover, a limitation in this study was the absence of a clinical sample. Future studies should investigate the psychometric properties of this measure in clinical samples with eating and weight-related disorders and further test the ability of this scale to discriminate cases from non-cases of eating disorders (e.g., anorexia, bulimia nervosa, binge eating disorder) or patients struggling with weight control difficulties (e.g., obesity). Nevertheless, our findings showed that the BISS is able to discriminate a group with higher levels of disordered eating behaviours from a group with lower levels. Taken together, our findings seem to support the relevance of this measure in clinical settings. The assessment of body image shame phenomenology seems particularly important given the implications that this painful emotion may have on the therapeutic process (e.g., motivation, disclosure in treatment and dropout rates; e.g., Goss \& Allan, 2009). Thus, future work should further investigate utility of the BISS in clinical settings and its sensitivity to therapeutic changes along psychological interventions.

Also, the significant associations found in the current study between the BISS and a measure of overall psychopathology, open new possibilities for further examining the role of body image shame on indicators of mental health, wellbeing and quality of life.

In conclusion, this study showed that BISS is a valid, robust, short and reliable measure of body image shame and related attitudes and behaviours. Moreover, this study adds to the existing knowledge on shame and on how physical appearance may be a source of shame, by presenting the development of the first scale that allows for the assessment of body image shame as a multifaceted response involving an external and an internal dimension. Hence, the BISS seems to be an important contribution for body image and eating-related problems' clinical and research fields. 


\section{REFERENCES}

Andrews, B., Qian, M., \& Valentine, J. (2002). Predicting depressive symptoms with a new measure of shame: the experience of shame scale. The British Journal of Clinical Psychology, 41, 29-33. doi: 10.1348/014466502163778

Arbuckle, J. (2008). Analysis of Moment Structures (AMOS) 17.0.0. Crawfordville, FL: AMOS Development Corporation.

Apóstolo, J., Mendes, A., \& Azeredo, Z. (2006). Adaptation to Portuguese of the Depression, Anxiety and Stress Scales (DASS). Revista Latino-Americana de Enfermagem, 14(6), 863-871. Retrieved from: http://www.scielo.br/pdf/rlae/v14n6/v14n6a06.pdf

Baron, M. \& Kenny, D. (1986). The moderator-mediator variable distinction in social psychological research: Conceptual, strategic, and statistical considerations. Journal of Personality and Social Psychology, 51, 1173-1182. doi: 10.1037/0022-3514.51.6.1173

Baumeister, R. F., \& Leary, M.R. (1995). The need to belong: Desire for interpersonal attachments as a fundamental human motivation. Psychological Bulletin, 117(3), 497-529. doi:10.1037/0033-2909.117.3.497

Bessenoff, G., \& Snow, D. (2006). Absorbing society's influence: Body image selfdiscrepancy and internalized shame. Sex Roles, 54(9/10), 727-731. doi: $10.1007 /$ s11199-006-9038-7

Brown, T. A. (2006). Confirmatory factor analysis for applied research. New York: Guilford.

Buote, M., Wilson, E, Strahan, J., Gazzola, B., \& Papps F. (2011). Setting the bar: Divergent sociocultural norms for women's and men's ideal appearance in realworld contexts. Body Image, 8, 322-334. doi:10.1016/j.bodyim.2011.06.002.

Carr T., Harris D., \& James C. (2000). The Derriford Appearance Scale (DAS-59): A new scale to measure individual responses to living with problems of appearance. British Journal of Health Psychology, 5(2), 201-215. doi: $10.1348 / 135910700168865$

Carr, T., Moss, T., \& Harris, D. (2005). The DAS24: A short form of the Derriford Appearance Scale (DAS59) to measure individual responses to living with 
problems of appearance. British Journal of Health Psychology, 10(2), 285-298. doi: $10.1348 / 135910705 \times 27613$

Castonguay, A., Brunet, J., Ferguson, L., Sabiston, C. (2012) Weight-related actual and ideal self-states, discrepancies, and shame, guilt, and pride: Examining associations within the process model of self-conscious emotions. Body Image, 9(4), 488-494. doi: 10.1016/j.bodyim.2012.07.003.

Cohen, D. (2001). Cultural variation: Considerations and implications. Psychological Bulletin, 127(4), 451-471. doi: 10.1037//0033-2909.127.4.451

Cooper, Z., \& Fairburn, C. G. (1987). The Eating Disorder Examination: A semistructured interview for the assessment of the specific psychopathology of eating disorders. International Journal of Eating Disorders, 6, 1-8. doi: 10.1002/1098-108X(198701)6:1<1::AID-EAT2260060102>3.0.CO;2-9

Conradt, M., Dierk, J., Schlumberger, P., Rauh, E., Hebebrand, Johannes \& Rief, W. (2007). Development of the Weight and Body-Related Shame and Guilt Scale (WEB-SG) in a Nonclinical Sample of Obese Individuals. Journal of Personality Assessment, 88(3), 317-327. doi:10.1080/00223890701331856

DeCoster, J. (1998). Overview of factor analysis. Retrieved from http://www.stathelp.com/notes.html.

Engeln-Maddox, R. (2006). Buying a beauty standard or dreaming of a new life? Expectations associated with media ideals. Psychology of Women Quarterly, 30, 258-266. doi: 10.1111/j.1471-6402.2006.00294.x

Fairburn, C. \& Beglin, S. (1994). Assessment of eating disorder psychopathology: Interview or self-report questionnaire? The International Journal of Eating Disorders, 16(4), 363-370. doi: 10.1002/1098-108X(199412)16:4<363::AIDEAT2260160405>3.0.CO;2-\#

Fairburn C. G., \& Cooper, Z. (1993). The Eating Disorder Examination (twelfth edition). In C. G. Fairburn \& G. T. Wilson (Eds.), Binge Eating: Nature, Assessment and Treatment (pp. 317-360). New York: Guilford Press.

Ferreira, C., Pinto-Gouveia, J., \& Duarte, C. (2013a). Physical appearance as a measure of social ranking: The role of a new scale to understand the relationship between weight and dieting. Clinical Psychology and Psychotherapy, 20(1), 55-66. doi: 10.1002/cpp.769 
Ferreira, C., Pinto-Gouveia, J., \& Duarte, C. (2013b). Self-compassion in the face of shame and body image dissatisfaction: Implications for eating disorders. Eating Behaviors, 14(2), 207-210. doi: 10.1016/j.eatbeh.2013.01.005

Fornell, C., \& Larcker, D. (1981). Evaluating structural equation models with unobservable variables and measurement error. Journal of Marketing Research, 18(1), 39-50. Retrieved from: http:/facultygsb.stanford.edu/larcker/PDF/6\%20Unobservable\%20Variables.pdf

Gatward, N. (2007). Anorexia nervosa: An evolutionary puzzle. European Eating Disorders Review, 15, 1-12. doi:10.1002/erv.718

Gilbert, P. (1992). Depression: The evolution of powerlessness. Hove: Guilford/Lawrence Erlbaum Associates.

Gilbert, P. (1997). The evolution of social attractiveness and its role in shame, humiliation, guilt and therapy. British Journal of Medical Psychology, 70, 113147. doi: 10.1111/j.2044-8341.1997.tb01893.x

Gilbert, P. (1998). What is shame? Some core issues and controversies. In P. Gilbert \& B. Andrews (Eds.), Shame: Interpersonal behaviour, psychopathology and culture (pp. 3-36). New York: Oxford University Press.

Gilbert, P. (2000). The relationship of shame, social anxiety and depression: The role of the evaluation of social rank. Clinical Psychology and Psychotherapy, 7, 174-189. doi: 10.1002/1099-0879(200007)7:3<174::AID-CPP236>3.0.CO;2-U

Gilbert, P. (2002). Body shame: a biopsychosocial conceptualisation and overview, with treatment implications. In P. Gilbert and J. Miles (Eds.), Body Shame: conceptualisation, research and treatment (pp. 3-54). London: Brunner.

Gilbert, P. (2007). The evolution of shame as a marker for relationship security. In J. Tracy, R. Robins \& J. Tangney (Eds.), The Self-Conscious Emotions: theory and research. (pp. 283-309). New York: Guilford.

Gilbert, P. \& McGuire, M. (1998). Shame, social roles and status: the psychobiological continuum from monkey to human. In P. Gilbert \& B. Andrews (Eds.), Shame: interpersonal behavior, psychopathology and culture, (pp. 99125). New York: Oxford University Press. 
Gilbert, P., Price, J., \& Allan, S. (1995). Social comparison, social attractiveness and evolution: How might they be related?. New Ideas in Psychology, 13, 149-165. doi: 10.1016/0732-118X(95)00002-X

Gilbert, S., \& Thompson, J. (2002). Body shame in childhood \& adolescence. In P. Gilbert \& J. Miles (Eds.), Body Shame (pp. 55-74). Hove: Brunner-Routledge.

Goss, K. \& Allan, S. (2009). Shame, pride and eating disorders. Clinical Psychology and Psychotherapy, 16, 303-316. doi: 10.1002/cpp.627

Goss, K., \& Gilbert, P. (2002). Eating disorders, shame and pride: A cognitivebehavioural functional analysis. In P. Gilbert, \& J. Miles (Eds.), Body shame: Conceptualisation, research and treatment (pp. 219-255). New York: Brunner Routledge.

Goss, K., Gilbert, P., \& Allan, S. (1994). An exploration of shame measure-I: the other as shamer scale. Personality and Individual Differences, 17, 713-717. doi:10.1016/0732-118X(95)00002-X

Grabhorn, R., Stenner, H., Stangier, U., \& Kaufhold, J. (2006). Social anxiety in anorexia and bulimia nervosa: The mediating role of shame. Clinical Psychology and Psychotherapy, 13, 12-19. doi:10.1002/cpp.463

Kim, S., Thibodeau, R., \& Jorgensen, R. (2011) Shame, guilt, and depressive symptoms: a meta-analytic review. Psychological Bulletin, 137(1) 68-96. doi: $10.1037 / \mathrm{a} 0021466$.

Kline, R. (2005). Principals and practice of structural equation modelling ( $2^{\text {nd }}$ ed.). New York: Guilford Press.

Lewis, M. (1992). Shame: the exposed self. New York: The Free Press.

Lewis, M. (2003). The role of the self in shame. Social Research: An International Quarterly of the Social Sciences, 70, 1181-1204.

Liotti, G. \& Gilbert, P. (2011). Mentalizing, motivation, and social mentalities: Theoretical considerations and implications for psychotherapy. Psychology and Psychotherapy: Theory, Research and Practice, 84, 9-25. doi: 10.1348/147608310X520094.

Lovibond, S. H. \& Lovibond, P. F. (1995). Manual for the Depression Anxiety Stress Scales $\left(2^{\text {nd }}\right.$ ed.). Sydney: Psychology Foundation. 
Machado, P. P. P. (2007). Versão Portuguesa do EDE-Q, $5^{a}$ edição [Portuguese Version of the EDE-Q, 5th edition]. Unpublished manuscript. University of Minho.

Matos, M., Pinto-Gouveia, J. \& Duarte, C. (2011). Other as shamer: Versão portuguesa e propriedades psicométricas de uma medida de vergonha externa [Other as shamer: Portuguese version and psychometric properties of a measure of external shame]. Manuscript submitted for publication.

Matos, M., Pinto-Gouveia, J. \& Gilbert, P. (2013). The effect of shame and shame memories on paranoid ideation and social anxiety. Clinical Psychology and Psychotherapy, 20, 334-349. doi: 10.1002/cpp.1766

McKinley, N. M. (1998). Gender differences in undergraduates' body esteem: The mediating effect of objectified body consciousness and actual/ideal weight discrepancy. Sex Roles, 39, 113-123. doi: 10.1023/A:1018834001203

McKinley, N. \& Hyde, J. (1996). The Objectified Body Consciousness Scale development and validation. Psychology of Women Quarterly, 20, 181-215. doi: 10.1111/j.1471-6402.1996.tb00467.x

Mikulincer, M. \& Shaver, P. (2005). Mental representations of attachment security: theoretical foundations for a positive social psychology. In M. W. Baldwin (Ed.), Interpersonal Cognition (pp. 233-266). New York: Guilford.

Myers, T., \& Crowther, J. (2009). Social comparison as a predictor of body dissatisfaction: A meta-analytic review. Journal of Abnormal Psychology, 115(4), 683-698. doi: 10.1037/a0016763

Noll, S., \& Fredrickson, B. (1998). A mediational model linking self-objectification, body shame, and disordered eating. Psychology of Women Quarterly, 22, 623636. doi: 10.1111/j.1471-6402.1998.tb00181.x

Pinto-Gouveia, J., Ferreira, C., \& Duarte, C. (2014). Thinness in the pursuit for social safeness: An integrative model of social rank mentality to explain eating psychopathology. Clinical Psychology and Psychotherapy, 21(2), 154-165. doi: $10.1002 /$ cpp. 1820

Puhl, R. \& Heuer, C. (2009). The stigma of obesity: A review and update. Obesity, 17, 941-964. doi: 10.1038/oby.2008.636 
Schore, A. N. (1994). Affect Regulation and the Origin of the Self: the neurobiology of emotional development. Hillsdale, NJ: Erlbaum.

Stice, E., Schupak-Neuberg, E., Shaw, H., \& Stein, R. (1994). Relation of media exposure to eating disorder symptomatology: An examination of mediating mechanisms. Journal of Abnormal Psychology, 103(4), 836-840. doi: 10.1037/0021-843X.103.4.836

Swan, S., \& Andrews, B. (2003). The relationship between shame, eating disorders and disclosure in treatment. British Journal of Clinical Psychology, 42(4), 367378. doi: 10.1348/014466503322528919

Tabachnick, B., \& Fidell, L. (2007). Using multivariate statistics. Boston, MA: Pearson Education, Inc.

Troop, N., Allan, S., Serpell, L., \& Treasure, J. (2008). Shame in women with a history of eating disorders. European Eating Disorders Review 16(6), 480-488. doi: 10.1002/erv.858.

Tangney, J. \& Dearing R. (2002). Shame and Guilt. New York: Guilford

Wiseman, C., Gray, J., Mosimann, J., \& Ahrens, A. (1992). Cultural expectations of thinness in women: An update. International Journal of Eating Disorders, 11, 85-89. doi: 10.1002/1098-108X(199201)11:1<85::AIDEAT2260110112>3.0.CO;2-T 
Table 1

Factorial Loadings and Communalities $(n=443)$

\begin{tabular}{|c|c|c|c|}
\hline Items & 1 & 2 & $h^{2}$ \\
\hline $\begin{array}{l}\text { 25. I feel uncomfortable in social situations because I feel that people may } \\
\text { criticize me because of my body shape. }\end{array}$ & .88 & .06 & .72 \\
\hline $\begin{array}{l}\text { 6. I avoid social situations (e.g., going out, parties) because of my physical } \\
\text { appearance. }\end{array}$ & .80 & .08 . & .58 \\
\hline $\begin{array}{l}\text { 34. The relationship I have with my physical appearance makes it difficult } \\
\text { for me to feel comfortable in social situations. }\end{array}$ & .81 & .10 & .75 \\
\hline $\begin{array}{l}\text { 33. I do not like to exercise in front of others because I am afraid of how } \\
\text { they might evaluate me. }\end{array}$ & .77 & .00 & .59 \\
\hline 32. My physical appearance makes me feel inferior in relation to others. & .71 & .11 & .62 \\
\hline $\begin{array}{l}\text { 18. The relationship I have with my body prevents me from having an } \\
\text { intimate relationship with someone. }\end{array}$ & .71 & .03 & .52 \\
\hline $\begin{array}{l}\text { 24. I avoid moving my body (for example, dancing) in public places } \\
\text { because I feel I am exposing my physical appearance to the criticism of } \\
\text { others. }\end{array}$ & .70 & .04 & .53 \\
\hline $\begin{array}{l}\text { 15. I choose clothes that hide parts of my body that I consider ugly or } \\
\text { disproportional. }\end{array}$ & .16 & .94 & .72 \\
\hline 29. There are parts of my body that I prefer to hide. & .04 & .89 & .75 \\
\hline 22. I feel bad about myself when I use clothes that reveal my body shape. & .06 & .81 & .72 \\
\hline 2. I avoid wearing tight clothes that reveal my body shape. & .01 & .76 & .59 \\
\hline $\begin{array}{l}\text { 21. I pay close attention to the movements and posture of my body to hide } \\
\text { parts that I do not like. }\end{array}$ & .07 & .73 & .60 \\
\hline 8. It bothers me to see my body undressed. & .17 & .64 & .57 \\
\hline 14. When I see my body in the mirror I feel I am a defective person. & .28 & .51 & .50 \\
\hline Eigenvalues & 7.118 & 1.620 & \\
\hline
\end{tabular}


1

2

3

4

5

6

7

8

9

10

11

12

13

14

15

16

17

18

19

20

21

22

23

24

25

26

27

28

29

30

31

32

33

34

35

36

37

38

39

40

41

42

43

44

45

46

47

48

49

50

51

52

53

54

55

56

57

58

59

60
Table 2

Global adjustment indices $(n=515)$

\begin{tabular}{ccccccc}
\hline & $X^{2} /(d f)$ & NFI & CFI & TLI & PCFI & RMSEA \\
BISS - & 4.57 & .93 & .94 & .93 & .79 & .08 \\
Initial & & & & & & \\
model & & & & & & \\
\hline BISS - & 3.40 & .95 & .96 & .96 & .78 & .07 \\
Final & & & & & & \\
model & & & & & & \\
\hline
\end{tabular}


Table 3

BISS product-moment Pearson correlations with other measures and Cronbach's alphas $(n=515)$

\begin{tabular}{lllll}
\hline & $\alpha$ & BISS & BISS_External & BISS_Internal \\
\hline OAS & .95 & $.53^{* * *}$ & $.55^{* * *}$ & $.46^{* * *}$ \\
SCPAS_Peers & .93 & $-.44^{* * *}$ & $-.41^{* * *}$ & $-.42^{* * *}$ \\
SCPAS_Models & .96 & $-.53^{* * *}$ & $-.46^{* * *}$ & $-.51^{* * *}$ \\
EDE-Q_Total & .93 & $.70^{* * *}$ & $.58^{* * *}$ & $.70^{* * *}$ \\
EDE-Q_Restraint & .77 & $.42^{* * *}$ & $.34 * * *$ & $.43^{* * *}$ \\
EDE-Q_Eating Concern & .71 & $.60^{* * *}$ & $.55^{* * *}$ & $.57 * * *$ \\
EDE-Q_Shape Concern & .91 & $.73^{* * *}$ & $.59^{* * *}$ & $.74^{* * *}$ \\
EDE-Q_Weight & .82 & $.67^{* * *}$ & $.55^{* * *}$ & $.67 * * *$ \\
Concern & & & & $.37^{* * *}$ \\
DEP & .89 & $.39 * * *$ & $.41^{* * *}$ & $.25^{* * *}$ \\
ANX & .80 & $.28^{* * *}$ & $.28^{* * *}$ & $.28^{* * *}$ \\
STR & .88 & $.31^{* * *}$ & $.30^{* * *}$ & $.41^{* * *}$ \\
BMI & & $.38^{* * *}$ & $.28^{* * *}$ & Through Physical \\
\hline Note. OAS $=$ Other as & Shamer Scale; SCPAS $=$ Social Comparison & Through
\end{tabular}
Appearance Scale; EDE = Eating Disorder Examination - Questionnaire; DEP, ANX, STR = Depression, Anxiety and Stress Scales of DASS-21; BMI = Body Mass Index.

$* * * p<.001$ 


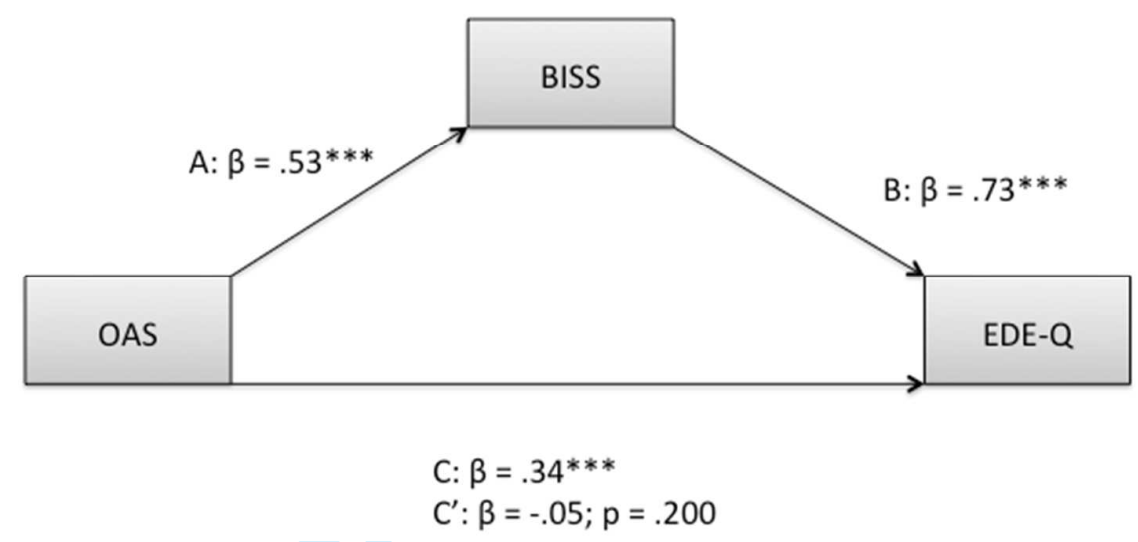

Figure 1. The association between external shame (independent variable; OAS) and eating psychopathology (dependent variable; EDE-Q), with body image shame (mediator; BISS) as a mediator $(n=515)$. A: the relation between the independent variable and the mediator; $\mathrm{B}=$ the relation between the mediator and the dependent variable; $\mathrm{C}=$ the direct effect between the independent and the dependent variables; $C$ ' the indirect effect of the independent variable on the dependent variable when controlling for the mediator; $* * * p<.001$ 
Figure 1. The association between external shame (independent variable; OAS) and eating psychopathology (dependent variable; EDE-Q), with body image shame (mediator; BISS) as a mediator $(n=515)$. A: the relation between the independent variable and the mediator; $\mathrm{B}=$ the relation between the mediator and the dependent variable; $\mathrm{C}=$ the direct effect between the independent and the dependent variables; $\mathrm{C}^{\prime}$ the indirect effect of the independent variable on the dependent variable when controlling for the mediator; $* * *$ $\mathrm{p}<.001$

$202 \times 94 \mathrm{~mm}(72 \times 72 \mathrm{DPI})$ 